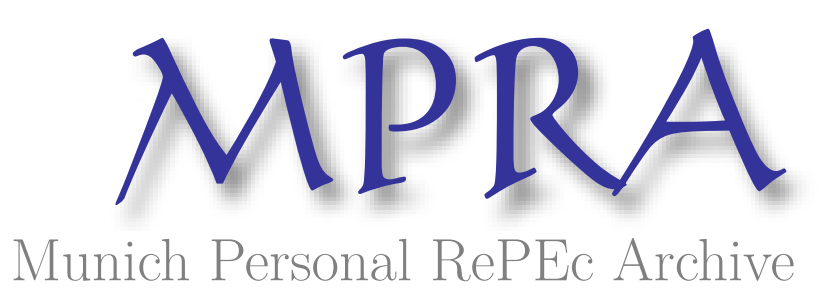

\title{
Income Inequality and Economic Growth
}

Shin, Inyong

Department of Economics, Asia University

31 March 2008

Online at https://mpra.ub.uni-muenchen.de/24397/

MPRA Paper No. 24397, posted 12 Aug 2010 21:06 UTC 


\title{
Income Inequality and Economic Growth
}

\author{
Inyong Shin *
}

\begin{abstract}
Despite the extensive existing literature on income inequality and economic growth, there remains considerable disagreement on the effect of inequality on economic growth. Existing literatures find either a positive or a negative relationship. In this paper, we attempt to theoretically examine that relationship with a stochastic optimal growth model. We make the disagreement clear within a single model. We conclude (i) that both are possible - that is, higher inequality can retard growth in the early stage of economic development, and can encourage growth in a near steady state, (ii) that income redistribution by high income tax does not always reduce income inequality. Income inequality can be reduced by higher income tax in a near steady state, but it cannot be reduced in the early stage of economic development, and (iii) that two government polices - rapid economic growth and low income inequality - can be achieved by low income tax in the early stage of economic development, but both cannot be achieved simultaneously in a near steady state.
\end{abstract}

keywords Income Inequality, Economic Growth, Progressive Tax

JLE Classification E64, H23, O47

\section{Introduction}

This paper examines the relationship between income inequality and economic growth. Income inequality refers to disparities in the distribution of income, that is, the gap between the rich and the poor in a country. What relationship exists between income inequality and economic growth? Let us take two pairs of familiar examples, 1) East Asian and South American countries, 2 ) the United States and France. One of the most common features in the East Asian countries, where economic growth has been high for the past 30 years, is the declining income inequality (World Bank 1993). South American countries, on the other hand, have experienced severe income inequality problems and economic downturn at the same time. Based on the case studies of East Asian and South American countries only, we may presume that there is a negative relationship between income inequality and economic growth. However, we can easily find out other cases of industrialized nations, such as the United States and France. In recent years, economic reports say that the economic growth rate of the United States is higher than that of France, and that the United States suffers higher income inequality than France does. ${ }^{1}$ Based on the case studies of the United States and France, we may presume that there is a positive relationship between income inequality and economic growth. Therefore it is not possible to simply state a conclusion on either a positive or negative relationship involving these two economic factors.

*Department of Economics, Asia University, 5-24-10 Sakai Musashino Tokyo 180-8629 Japan, Tel.: +81-422-365259, Fax: +81-422-36-4042, E-mail addredss: shin@asia-u.ac.jp

${ }^{1}$ The average annual economic growth rate, measured real GDP per capita, of the United States and France from 1990 to 2007 are $1.916 \%$ and $1.322 \%$, respectively. The figures are calculated by the author using the Penn World Table 6.3. 
Concerning the relationship between income inequality and growth performance, we can find both possibilities, a positive or negative, from the existing literature such as the two pairs of examples mentioned above. This paper aims to explain the disagreement consistently using one theoretical model. The results of the early research are summarized in Table $1 .^{2}$ The research in the first row of Table 1 conclude a negative relationship between income inequality and economic growth. Oppositely, the research in the second row conclude a negative relationship between the two variables. The research in the third row conclude that there is a nonmonotonic relationship like the inverted $U$ shape. The research in the last row conclude that no unique relationship is present or that it is inconclusive.

For example, Barro (2000) concludes that the effect of income inequality on economic growth is different contingent on the state of economic development. Income inequality in poor countries retards economic growth, but income inequality in rich countries encourages economic growth. Using the panel data, Barro (2000) shows that the effect of income inequality on economic growth is negative in countries with GDP per capita below 2070, and is conversely positive in countries with GDP per capita over 2070. Examining the two pairs of samples mentioned above, if we regard Asian countries and South American countries as examples of developing countries and the United State and France as examples of developed countries, the case of these samples is consistant with Barro (2000)'s conclusion.

Table 1: Previous literatures

The relationship between income inequality and economic growth

\begin{tabular}{l|l}
\hline Relationship & Authors \\
\hline 1) Negative & $\begin{array}{l}\text { Murphy et al. (1989), Perotti (1993), Alesina and Rodrik (1994), } \\
\text { Persson and Tabellini (1994), Perotti (1996), Alesina and Perotti } \\
\text { (1996), Acemoglu (1997), Helpman (2004), Tachibanaki (2005), } \\
\text { Sukiassyan (2007), etc. }\end{array}$ \\
\hline 2) Positive & $\begin{array}{l}\text { Okun (1975), Bourguignon (1990), Benabou (1996), Li and Zou } \\
(1998), \text { Aghion and Howitt (1998), Forbes (2000), etc. }\end{array}$ \\
\hline 3) Inverted U & Chen (2003) etc. \\
\hline 4) Not unique or & $\begin{array}{l}\text { Amos (1988), Barro (2000), Banerjee and Duflo (2003), Weil } \\
\text { Inconclusive }\end{array}$ \\
\hline
\end{tabular}

The positive relationship between income inequality and economic growth might be explained as follows. In developed countries, the saving rate of rich people is higher than that of the poor. Income redistribution from rich people to poor people reduces the saving rate of the economy as a whole and thus could lead to a decline in economic growth. Another reason is that the income redistribution could lower the incentive for the rich to work hard, and that could also lead to an economic growth decline. As a result, we can infer that income equality makes economic growth lower, and income inequality makes it higher.

Meanwhile, the negative relationship between income inequality and economic growth might be explained as follows. In developing countries, poor people are under credit constraint. They do not have the opportunity of investing, and extremely poor people in income inequality cannot even participate in product activity. Income inequality might lead to political and social instability, and consequently to economic growth decline. As a result, we can infer that income inequality

\footnotetext{
${ }^{2}$ The existing literatures in Table 1 are using different data and analysis methods, respectively. See, Table 1 (page 38) in Sukiassyan (2007) for details.
} 
makes economic growth lower and income equality makes it higher. ${ }^{3}$

Which explanation is more reasonable? In this paper, we attempt to make the disagreement comprehensible within a single framework. We examine the relationship theoretically using a stochastic optimal growth model composed by heterogeneous agents. ${ }^{4}$ We also introduce a progressive tax system into our model and get a numerical solution. We can conclude, in advance, (i) that depending on the state of development, both are possible, that is, higher inequality can retard growth in the early stage of economic development and can encourage growth in a near steady state. This agrees with the Barro (2000)'s result, which shows experimental results using panel data. We make the disagreement clear within the single model. (ii) Moreover, income redistribution by high income tax does not always reduce income inequality. Income inequality can be reduced by higher income tax in a near steady state, but it cannot be reduced in the early stage of economic development. Lastly, (iii) the two government polices - rapid economic growth and low income inequality - can be achieved by low income tax in the early stage of economic development, but both cannot be achieved simultaneously in a near steady state.

This paper is organized as follows. In section 2, we draw the relationship from Kuznets curve and convergence theory of the new classical. In section 3, we introduce a heterogeneous model including a progressive tax system. In section 4, we solve the model numerically, interpret the result and discuss the implications. We then propose a conclusion and develop ideas for the further research in section 5. Finally, we include an appendix that explains more about the numerical solution results at different value parameters.

\section{Kuznets Curve and Convergence Theory}

Considering Kuznets curve and the convergence theory simultaneously would make us doubt "monotonous relations" - monotonic increasing and monotonic decreasing -, which are insisted by much of the early research. The relations between the Gini coefficient and the economic growth rate may easily be shown through using a simple four quadrant diagram like the one in Figure 1.

First, we refer to the relationship between the state of economic development and income inequality. Kuznets curve is the curve that shows the relationship between the stage of economic development and income inequality (Kuznets 1955). Initially, income inequality increases at the early stage of economic development while a country is developing and reaches a peak of inequality. Second, income inequality declines at the matured stage of economic development. If Kuznets curve is correct, the relationship between GDP per capita and the Gini coefficient could be drawn as shown in the fourth quadrant diagram (IV)..$^{5}$ The vertical axis $(\downarrow)$ of the quadrant diagram shows GDP per capita from less GDP above to more GDP below. The horizontal axis $(\rightarrow)$ shows the Gini coefficient from less inequality on the left to more inequality on the right.

Next, we refer to the relationship between the level of GDP per capita and the economic growth rate. According to the convergence theory, if the sample is limited to the original OECD countries, the absolute $\beta$ convergence can be applied (Baumol 1986, etc.). On the other hand, if the sample is expanded to developing countries, the absolute $\beta$ convergence cannot be applied (Abramovitz 1986, De Long 1988, etc.). However, it is pointed out that a certain kind of convergence phenomenon, that is the conditional convergence, is found between the initial per capita GDP and the economic growth even though the sample is expanded to developing countries when

\footnotetext{
${ }^{3}$ Details about the reasons can be found in Helpman (2004), Tachibanaki (2005), Weil (2005), etc.

${ }^{4}$ The analyses with a optimal growth model are few even though there are many analyses of cross country data.

${ }^{5}$ However, Kuznets's inverted U-shape hypothesis was rejected by some recent research (e.g. Bourguignon 1990, etc.). Amos (1988) and Tachibanaki (2005) propose a hypothesis the third curves (Cubic) in a part of advanced country exceeding inverted U-shape.
} 


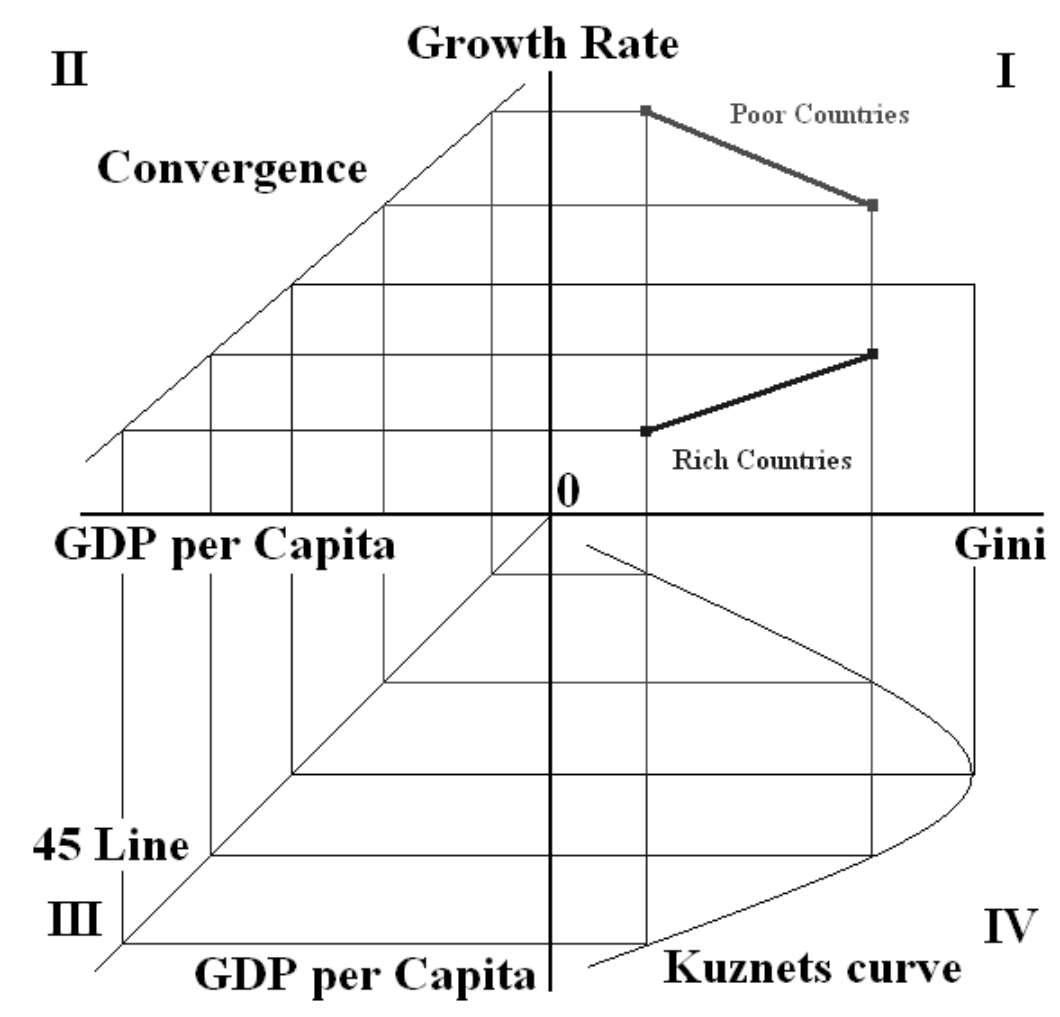

Figure 1: Conceptual Graph

other conditions, such as the different saving rate, the population growth rate, and human capital, are well controlled (Mankiw et al. 1992, etc.). After all, it is assumed that the economic growth rate is high in (initially) poorer countries and economic growth rate is lower in (initially) rich countries if other conditions are well controlled in convergence theory. If the convergence theory is correct, the relationship between GDP per capita and the economic growth rate could be drawn as shown in the second quadrant diagram (II). The horizontal axis $(\leftarrow)$ of the second quadrant diagram shows GDP per capita from less GDP on the right to more GDP on the left, and the vertical axis $(\uparrow)$ shows the economic growth rate from lower growth rate below to higher growth rate above. The third quadrant diagram (III) is a 45-degree line.

The relationship between the Gini coefficient and the economic growth rate is easily shown through the second, the third, and the fourth quadrant diagrams to the first quadrant diagram (I). It is easy to understand that there is no unique relationship between the Gini coefficient and the economic growth rate as shown in Figure 1. Two relationships appear: one is the upwardsloping curve by the high income countries and the other is the downward-sloping curve by the low income countries. This result agrees with Figure 2 (page 19) of Barro (2000) that uses the panel data. The left panel of his Figure 2 shows that income inequality retards economic growth in developing countries. On the contrary, the right panel shows that income inequality encourages economic growth in developed countries.

Not only a monotonous relationship but also a complex one between income inequality and economic growth rate is expected from Figure 1. We will explain the complex relationship using a stochastic optimal growth model in the next section. 


\section{Model}

We use a heterogeneous agent growth model. ${ }^{6}$ To compare the difference of income inequality among the economies, we introduce a progressive tax system and apply a different tax rate to our model. $^{7}$

\subsection{Households}

The economy consists of many infinitely lived individuals. For simplification, each household is assumed to be composed of one agent. Hereafter, the household and the agent will be used in the same meaning. We assume no population growth. In particular, we consider a continuum of agents of total mass equal to one.

\subsubsection{Utility}

Households maximize their preference with their streams of consumption according to

$$
U=E_{0} \sum_{t=0}^{\infty} \beta^{t} u\left(c_{t}\right),
$$

where $E_{0}$ is the conditional expectation on the information set at period 0 and $\beta(0<\beta<1)$ is the subjective discount factor. The agent's instantaneous utility function $u\left(c_{t}\right)$ is twice continuously differentiable, increasing and concave in his/her consumption $c_{t}$ and has the following form:

$$
u\left(c_{t}\right)=\frac{c_{t}^{1-\sigma}-1}{1-\sigma}
$$

where $\sigma(\sigma>0)$ denotes the coefficient of relative risk aversion.

\subsubsection{Employed and Unemployed}

To show the heterogeneous agent's characteristic, the uncertainty is introduced in the employment status of households. Households are under the uncertainty of employment. $\epsilon \in\{e, u\}$ represents their employment status. If $\epsilon=e \quad(\epsilon=u)$, the agent is employed (unemployed). The individual specific employment state is assumed to follow a first-order Markov chain. The conditional transition matrix is given by:

$$
\pi\left(\epsilon^{\prime} \mid \epsilon\right)=\operatorname{Prob}\left\{\epsilon_{t+1}=\epsilon^{\prime} \mid \epsilon_{t}=\epsilon\right\}=\left(\begin{array}{ll}
P_{u u} & P_{u e} \\
P_{e u} & P_{e e}
\end{array}\right)
$$

where we denote next period's variable by prime $\left({ }^{\prime}\right)$. For example, $P_{u u}$ is the probability that an agent will be unemployed in period $t+1$ continuously, given that the agent is unemployed in period $t . P_{u e}$ is the probability that an agent will be employed in period $t+1$, given that the agent is unemployed in period $t$. The explanations of $P_{e u}$ and $P_{e e}$ are omitted. Households know the law of motion of the employment status $\epsilon_{t}$.

\footnotetext{
${ }^{6}$ Inequality does not occur in homogeneous agent model because every agent is the same as shown in the name.

${ }^{7}$ To invent the difference of the inequality degree among each economy, we controls the progressive tax rate (maximum tax rate). The reason why there is a difference of the inequality degree among each country is not only because of the progressive tax. It is thought that the difference is influenced from other taxes systems (for instance, inheritance tax, etc.) and the social security systems (for instance, pension system, etc.). However, we focus only on the progressive tax system in this paper.
} 


\subsubsection{Budget Constraint}

We assume that households have their initial asset $a_{0}$ in period 0 , and households have unit labor force in each period. ${ }^{8}$ Households earn interest income and wage income every period. Households earn $a_{t} r_{t}$ as interest income in period $t$, where $a_{t}$ and $r_{t}$ are asset and interest rate in period $t$, respectively. If households are employed $\left(\epsilon_{t}=e\right)$ in period $t$, their wage income will be $w_{t}(\geq 0)$ in period $t$. If unemployed $\left(\epsilon_{t}=u\right)$, their wage income $w_{t}$ will be 0 . Let us denote $m$ as the aggregate income, which is the sum of the income from assets and the labor income. Then, the aggregate income of the households in $t$ is

$$
m_{t}=\left\{\begin{array}{llr}
a_{t} r_{t}+w_{t}, & \text { if } \quad \epsilon_{t}=e \\
a_{t} r_{t}, & \text { if } \quad \epsilon_{t}=u
\end{array}\right.
$$

by the status of work in period $t$.

We assume that the aggregate income $m_{t}$ is taxed at rate $\tau_{t}$ in period $t$, and that the unemployment benefit $b_{t}$ is provided by the government if the agent is unemployed $\left(\epsilon_{t}=u\right)$ in period $t$. Unemployment benefit is not taxed. Then, the households face the following budget constraint:

$$
a_{t+1}= \begin{cases}a_{t}+\left(1-\tau_{t}\right) m_{t}-c_{t}=a_{t}+\left(1-\tau_{t}\right)\left(r_{t} a_{t}+w_{t}\right)-c_{t}, & \text { if } \quad \epsilon_{t}=e \\ a_{t}+\left(1-\tau_{t}\right) m_{t}+b_{t}-c_{t}=a_{t}+\left(1-\tau_{t}\right) r_{t} a_{t}+b_{t}-c_{t}, & \text { if } \quad \epsilon_{t}=u .\end{cases}
$$

\subsubsection{Progressive Tax System}

Before specifying tax rate $\tau_{t}$, for the convenience of the explanation, we define $T_{t}$ as base of taxation and assume $T_{t}$ as the following:

$$
T_{t}=\eta \exp \left(\phi \frac{m_{t}}{x_{t}}\right)
$$

where $\eta(\eta>0), \phi(\phi>0)$ are constants and $x_{t}$ denote assessment index in period $t .{ }^{9}$ We assume that the tax rate $\tau_{t}$ depends on $T_{t}$ in Eq.(6).

$$
\tau_{t}=\left\{\begin{array}{lll}
\tau^{l}, & \text { if } \quad T_{t} \leq \tau^{l} \\
T_{t}, & \text { if } \quad \tau^{l} \leq T_{t}<\tau^{h} \\
\tau^{l}, & \text { if } \quad \tau^{h} \leq T_{t}
\end{array}\right.
$$

where $\tau^{l}, \tau^{h}\left(0 \leq \tau^{l} \leq \tau^{h}<1\right)$ are constants, which mean minimum tax rate and maximum tax rate, respectively.

\subsubsection{Unemployment Benefit}

Unemployment benefit $b_{t}$ in period $t$ is assumed as follows:

$$
b_{t}=\psi w_{t}
$$

where $\psi(0 \leq \psi<1)$ is a constant. Eq.(8) means that the unemployment benefit is paid in proportion to wage income $w_{t}$ but the unemployment benefit provided is less than the employed agent's wage for granted.

\footnotetext{
${ }^{8}$ Even though he/she is unemployed, which means that he/she gets more leisure time than an employed agent does, this does not affect on his/her utility function in our model, because leisure time is not included in his/her utility function Eq.(2).

${ }^{9}$ Our model does not handle $\eta, \phi$ as control variables. Our model is not an optimal taxation model.
} 


\subsubsection{Asset Distribution}

We define $f(\epsilon, a)$ as the asset distribution function among households. For instance, the density function $f(\epsilon, \bar{a})$ is the frequency of the agent who has his/her asset $\bar{a}$ and is in employed status. Because we assume that agents are continuously expressible in unit interval [0,1], Eq.(9) is filled.

$$
\sum_{\epsilon_{t} \in\{e, u\}} \int f_{t}\left(\epsilon_{t}, a_{t}\right) d a_{t}=1, \quad \forall t .
$$

Moreover, we obtain the dynamic of the asset distribution as follows

$$
f_{t+1}\left(\epsilon_{t+1}, a_{t+1}\right)=\sum_{\epsilon_{t} \in\{e, u\}} \pi\left(\epsilon_{t+1} \mid \epsilon_{t}\right) f_{t}\left(\epsilon_{t}, a_{t}\right) .
$$

\subsection{Government}

Government expenditures consist of unemployment benefits, which is financed by the aggregate income tax. The government budget is assumed in every period as the following:

$$
\sum_{\epsilon_{t} \in\{e, u\}} \int \tau_{t} m_{t} f_{t}\left(\epsilon_{t}, a_{t}\right) d a_{t} \geq \int b_{t} f_{t}\left(u, a_{t}\right) d a_{t}, \quad \forall t
$$

Eq.(11) does not necessarily express as the balanced budget of the government because Eq.(11) is an inequality $(\geq)$. ${ }^{10}$ We assume that the surplus of the government budget does not affect the utility and the production in this economy at all.

\subsection{Production}

Firms are owned by the households, and maximize their profits with respect to their labor and capital demand. No technological progress in production is assumed for the simplification. Production function $F\left(K_{t}, N_{t}\right)$ is characterized by constant returns to scale using capital $K_{t}$ and labor $N_{t}$ as input:

$$
y_{t}=F\left(K_{t}, N_{t}\right)=K_{t}^{\alpha} N_{t}^{1-\alpha},
$$

where $y_{t}$ is the output in period $t$ and $\alpha(0<\alpha<1)$ is the capital share, which is a constant. $K_{t}$ and $N_{t}$ denote aggregate capital stock and aggregate employment in this economy, respectively. ${ }^{11}$

$$
\begin{gathered}
K_{t}=\sum_{\epsilon \in\{e, u\}} \int a f(\epsilon, a) d a, \\
N_{t}=\int f(e, a) d a .
\end{gathered}
$$

\footnotetext{
${ }^{10}$ It is also possible to assume the balanced budget of a government. However, it requires considerable time for calculation; we treat the inequality $(\geq)$ in this paper.

${ }^{11}$ Aggregate employment $N_{t}$ is a constant because of no population growth and the utility function without leisure time. $N_{t}$ is decided based on the status conditional transition matrix of Eq.(3).
} 


\subsection{Market Clearance}

In a market equilibrium, factors are compensated according to their marginal products and profit is zero:

$$
\begin{aligned}
& r_{t}=\alpha\left(\frac{K_{t}}{N_{t}}\right)^{\alpha-1}-\delta, \\
& w_{t}=(1-\alpha)\left(\frac{K_{t}}{N_{t}}\right)^{\alpha},
\end{aligned}
$$

where $\delta$ denotes the depreciation rate of capital.

\section{Transition Dynamics}

\subsection{Computation}

To solve this problem, we introduce the Bellman equation and use the grid search method. ${ }^{12}$

\subsubsection{Bellman Equation and Value Function}

The value function can be expressed recursively by the Bellman equation as follows: ${ }^{13}$

$$
V(\epsilon, a, f)=\max _{\left\{c, a^{\prime}\right\}}\left\{u(c)+\beta E\left\{V\left(\epsilon^{\prime}, a^{\prime}, f^{\prime}\right)\right\}\right\}
$$

subject to the household budget constraint, the government budget constraint, the employment status, and the asset distribution. Households' value function $V$ is a function of employment status $(\epsilon)$, asset $(a)$ and asset distribution $(f(\epsilon, a))$. For a detailed way in solving this, refer to Ríos-Rull (1999) and Heer and Maussner (2005).

\subsubsection{Parameters}

Most of the parameter values for our calculation are the values used in Heer and Maussner (2005). The parameters $\eta, \phi, \tau^{l}, \tau^{h}$, which do not exist in Heer and Maussner (2005), are decided arbitrarily. The parameter values that we use to calculate are the following: $\alpha=0.36, \beta=0.995$, $\sigma=2.5, \tau^{l}=0.1, \tau^{h}=0.2,0.3,0.4,0.5,0.6,0.0, \eta=0.1, \phi=0.5, \psi=0.05, \delta=0.05$, and the employment transition matrix is as follows: 14

$$
\left(\begin{array}{ll}
P_{u u} & P_{u e} \\
P_{e u} & P_{e e}
\end{array}\right)=\left(\begin{array}{ll}
0.5000 & 0.5000 \\
0.0435 & 0.9565
\end{array}\right)
$$

And the assessment index $x_{t}$ of period $t$ is assumed to be $K_{t}$.

\subsubsection{Grid Search}

We use the grid search to maximize the Bellman equation. In using the grid search, we have to decide the range of control variables and the number of grid in advance.

\footnotetext{
${ }^{12}$ See Judd (1998) and Heer and Maussner (2005) for the grid search method.

${ }^{13}$ Affixing character $t$ that shows period $t$ is omitted. We denote the next period's variable by prime $(\prime)$.

${ }^{14}$ We consider the case of $\tau^{h}=0.0$ as benchmark. We compare the models with and without income tax. In case of $\tau^{h}=0.0$, we also put $\tau^{l}=0.0$.
} 
We choose an equispaced grid $\mathcal{A}=\left\{a_{1}, \cdots, a_{n}\right\}=\{0.1, \cdots, 600\}$ for asset $a$ with $n=101$ nodes. For the aggregate capital stock $K$, we also choose an equispaced grid $\mathcal{K}=\left\{K_{1}, \cdots, K_{n_{K}}\right\}=$ $\{50, \cdots, 400\}$ with $n_{K}=6$ nodes. The finer the grid, the closer we get to the true solution of the problem. But the finer the grid, the more time we need to calculate. We choose a coarse grid for $K$ and use linear interpolation to approximate the value function at point off the grid points.

\subsubsection{Initial Asset Distribution}

We decide on an initial asset distribution for calculation. We assume that the initial asset distribution is a uniform distribution that has the interval of left $40 \%$ range of $\mathcal{A}$, that is, the initial asset distribution is a uniform distribution over the interval $[0.1,240] .{ }^{15}$ The average capital stock is $K=120 .{ }^{16} f_{0}\left(\epsilon_{0}, a_{0}\right)$ is a uniform distribution with interval [0.1,240] and $\sum_{\epsilon_{0} \in\{e, u\}} \int a_{0} f_{0}\left(\epsilon_{0}, a_{0}\right) d a_{0}=120$.

\subsubsection{Partial Information}

To solve the Bellman equation of Eq.(17), the information on assets distribution $f(\epsilon, a)$ is necessary. We use only the first moment of the assets distribution as information on distribution $f(\epsilon, a) \cdot{ }^{17}$ In other words, we use only $K$ as the information on distribution $f(\epsilon, a)$. Then, the Bellman equation Eq.(17) can be rewritten as follows

$$
\tilde{V}(\epsilon, a, K)=\max _{\left\{c, a^{\prime}\right\}}\left\{u(c)+\beta E\left\{\tilde{V}\left(\epsilon^{\prime}, a^{\prime}, K^{\prime}\right)\right\}\right\} .
$$

where we denote $\tilde{V}(\epsilon, a, K)$ as another value function instead of $V(\epsilon, a, f)$ in Eq.(17). $f$ in Eq.(17) is changed to $K$ in Eq.(18). Krusell and Smith (1997) show that linear functions are very good predictiors of the higher moments. We follow Krusell and Smith (1997), therefore we employ a log linear approximation for the law of motion of the capital stock as follows:

$$
\ln K^{\prime}=\gamma_{0}+\gamma_{1} \ln K
$$

where $\gamma_{0}$ and $\gamma_{1}$ are constants.

\subsection{Results}

If we solve the optimization problem from the setting mentioned above, we can get the optimal paths of the assets distribution $f(\epsilon, a)$, the capital stock $K$, and the output $y$, etc. We calculate the optimal transitional paths from $t=0$ to $t=2,000$. The paths of each economic variables were placed in the range that we set up in Section 4.1.3 and the paths converged after $t=2,000$ as seen later.

\subsubsection{Dynamics of Asset Distribution}

Figure 2 shows the dynamics of asset distribution $f(\epsilon, a)$ from $t=0$ to $t=2,000$. Figure 2 (1) to (6) show how this initial asset distribution changes with the flow of time. Each vertical axis

\footnotetext{
${ }^{15}$ We use two kinds of uniform distribution as initial property distribution. Another one is a uniform distribution that has the interval of left $15 \%$ to $25 \%$ range of $\mathcal{A}$, that is, the initial asset distribution is uniform distribution over the interval $[90,150]$. These calculation results are shown in Figure 9 and Figure 10 in Appendix.

${ }^{16}$ As precisely mentioned, the interval of the initial uniform distribution is $\left[\begin{array}{ll}0.1241 .851\end{array}\right]$ and $K=120.975$. In another case, the interval of the initial uniform distribution is [89.637 152.313] and $K=120.975$.

${ }^{17}$ Krusell and Smith (1997) show that approximating the wealth distribution by its first monoment is sufficiently good, and the forecast error due to the omission of higher moments is extremely small.
} 
(1) Benchmark

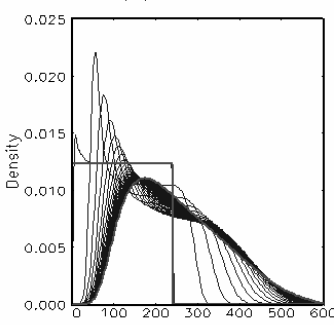

(4) $\tau^{\mathrm{h}}=0.4$

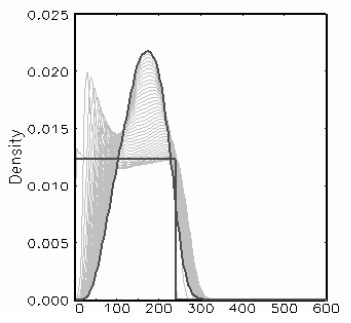

(2) $\tau^{\mathrm{h}}=0.2$

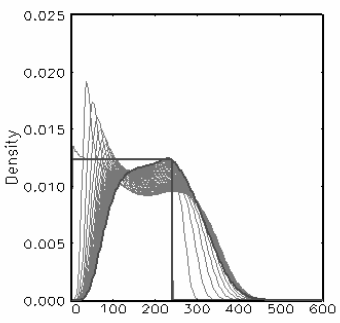

(5) $\tau^{h}=0.5$

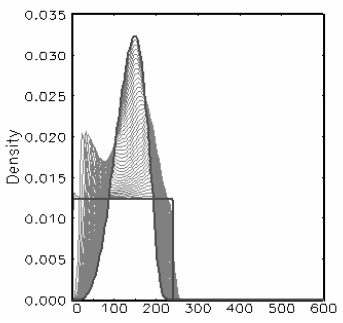

(3) $\tau^{\mathrm{h}}=0.3$

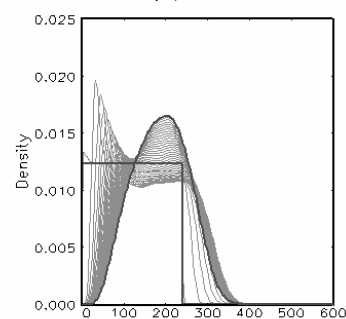

(6) $\tau^{h}=0.6$

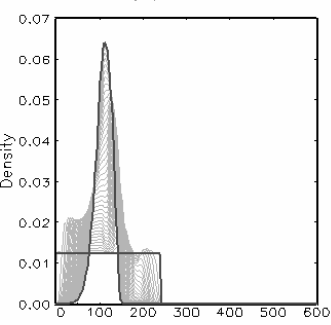

Figure 2: Dynamics of Asset Distribution

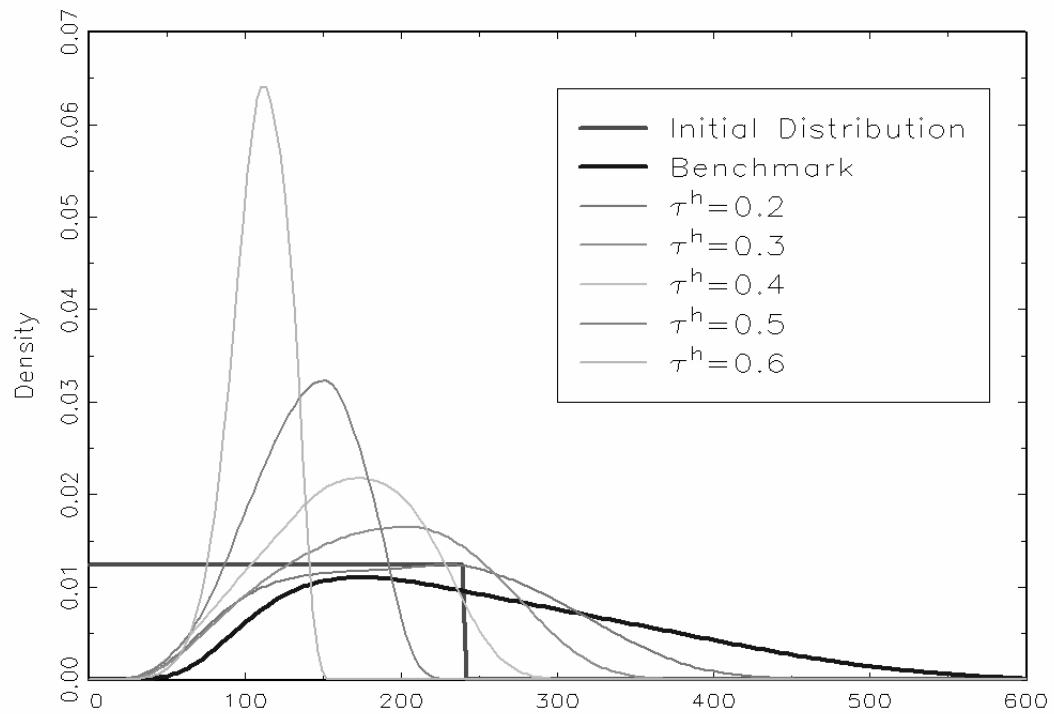

Figure 3: Comparison of Assets Distribution

shows density, and each horizontal axis shows the asset. To show the effect of progressive tax rate on asset distribution, we choose $\tau^{h}=0.0$ (=benchmark), 0.2, 0.3, 0.4, 0.5, 0.6. Each panel in Figure 2 shows the results. The thick rectangular lines show the initial asset distribution which is a uniform distribution with interval $[0.1,240]$.

The mountain shaped thick lines are the asset distribution at a steady state. The narrow lines show the asset distributions every 10 period on an optimal path. We can see that the initial uniform distributions change to a mountain shape distributions.

To compare the difference depending on progressive tax rate $\tau^{h}$, we collect the initial asset distribution and the asset distribution on a steady state in Figure 2 (1) to (6) in Figure 3. The initial asset distributions in Figure 2 (1) to (6) are the same. 
(1) Copital Stock

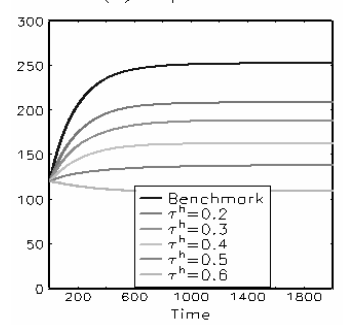

(2) Output

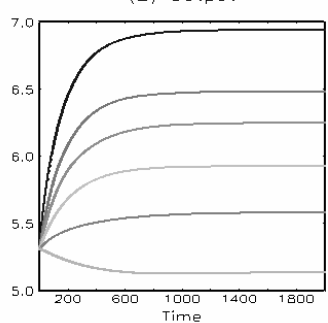

(3) Growth Rote

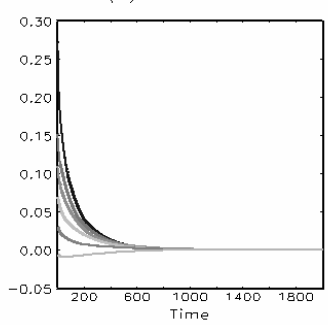

Figure 4: Capital Stock, Output and Growth Rate

The differences of the asset distribution on a steady state are as follows: when the progressive tax rate $\tau^{h}$ is high, the distribution is slim, and when the progressive tax rate $\tau^{h}$ is low, the distribution is wide; when the progressive tax rate $\tau^{h}$ is high, the distributions stay on the left side, and when the progressive tax rate $\tau^{h}$ is low, the distributions shift farther toward the right side. We can conclude that when the progressive tax rate is high, the economy has a low steady state and is more equal.

\subsubsection{Capital Stock, Output, and Growth Rate}

Figure 4 shows the time paths of capital stock, output, and growth rate. The vertical axes in Figure 4 (1) to (3) show the capital stock, the output, and the growth rate, respectively, and each horizontal axis shows the time. The capital stock in Figure 4 (1) equals the average of the asset distribution in Figure 2. ${ }^{18}$

In Figure 4 (1), when the progressive tax rate $\tau^{h}$ is higher, the capital stock is less, and vice versa. When the progressive tax rate $\tau^{h}$ is extremely high (here, $\tau^{h}=0.6$ ), the capital stock decreases, and as a consequence, it is less than the initial values. High progressive tax rate makes the capital accumulation slow down relatively. As a result, in case of high progressive tax rate, the capital stock on a steady state is smaller compared with that of low progressive tax rate case.

In Figure 4 (2), when the progressive tax rate $\tau^{h}$ is higher, the output is less, and vice versa. When the progressive tax rate $\tau^{h}$ is extremely high (here, $\tau^{h}=0.6$ ), the output decreases, and as a consequence, it is also less than the initial values. In case of a high progressive tax rate, the capital accumulation is slow, and the output corresponding to the small capital stock is also small. ${ }^{19}$

In Figure 4 (3), when the progressive tax rate $\tau^{h}$ is higher, the growth rate is lower, and vice versa. When the progressive tax rate $\tau^{h}$ is extremely high (here, $\tau^{h}=0.6$ ), the growth rate is minus. High progressive tax rate retards the economic growth rate.

\subsubsection{Dynamics of Inequality}

Figure 5 shows the change of the inequality, depending on time. The vertical axes in Figure 5 (1) to (3) show the income ratio, the Gini coefficient, and the polarization index, respectively. ${ }^{20}$ The income ratio is caculated, the ratio of the asset of the $20 \%$ of households with the highest asset

\footnotetext{
${ }^{18}$ See Eq.(13) for the reason.

${ }^{19}$ Labor supply does not depend on the progressive tax rate, and it is a constant. The labor supply depends on the conditional transition matrix $\pi$.

${ }^{20}$ Details about the polarization index can be found in Wolfson (1994).
} 


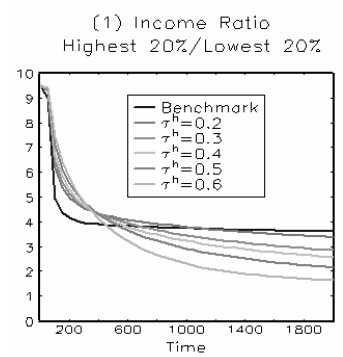

(2) Gini Coefficient

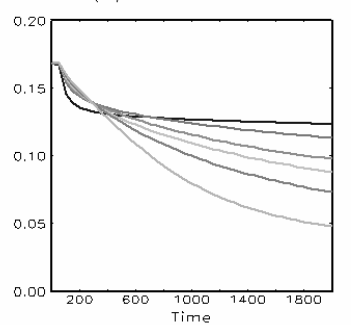

(3) Polarizatian index

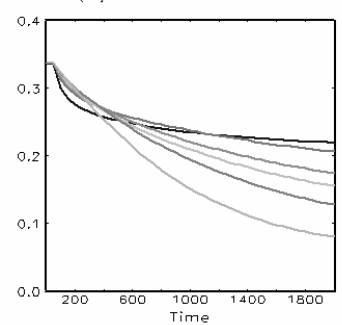

Figure 5: Dynamics of Equality and Inequality

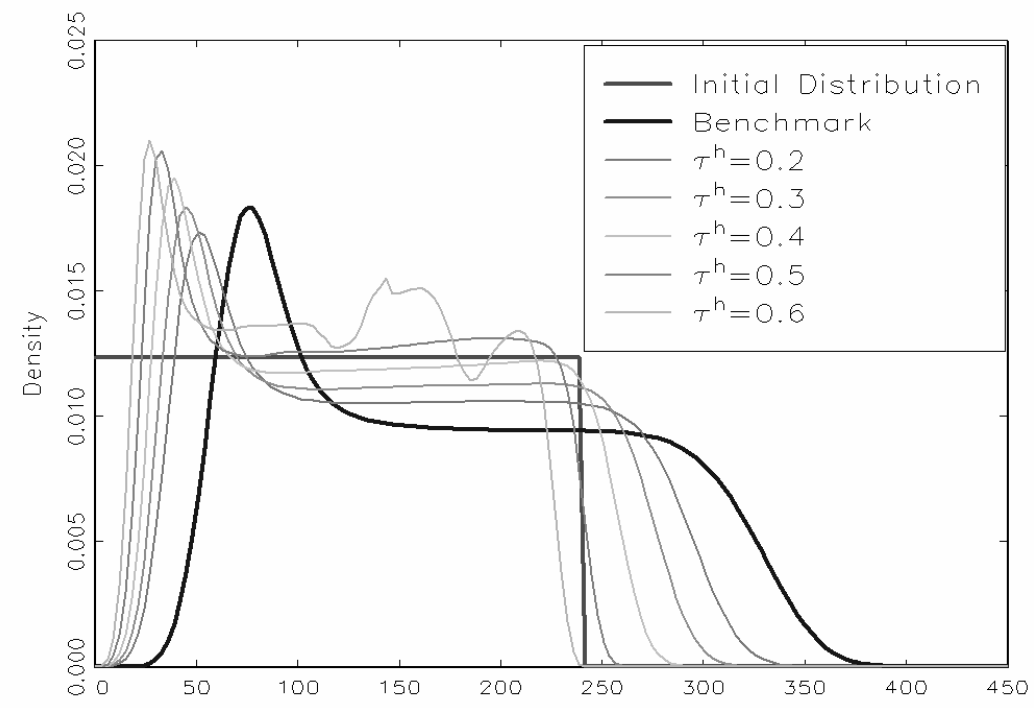

Figure 6: Income Distribution at Early Stage of Development

to that of the $20 \%$ of households with the lowest asset. The lower the value is, the more equal the economy is, and the higher the value is, the less equal the economy is. Each horizontal axis shows the time.

The results are quite similar across the three panels of Figure 5 in that the reverse of the values occurs in each panel. At a near steady state, the economy with higher $\tau^{h}$ is equal. But at a early stage of development, the economy with lower $\tau^{h}$ is equal. Figure 5 (1) to (3) obtain the same result. The reverse results mean that the effect of progressive tax on income inequality is deferent depending on the state of development.

To examine in details the reason why such reverse occurs, we draw the asset distributions at the early stage of development. Figure 6 shows the asset distributions at $t=10$. The degree of the shift of the distribution is different depending on $\tau^{h}$. When $\tau^{h}$ is the lower, the right shift of the left side (the lowest quintile) is bigger than that of the right side (the highest quintile). On the other hand, when $\tau^{h}$ is higher, the right shift of the left side (the lowest quintile) is smaller than that of the right side (the highest quintile).

Castaneda et al. (1998) shows using a general equilibrium model that the income of the lowest quintile is more volatile. Based on our results, we can infer that when $\tau^{h}$ is lower, the capital accumulation is fast and the shift of poor people to the right side occurs much faster. As a 


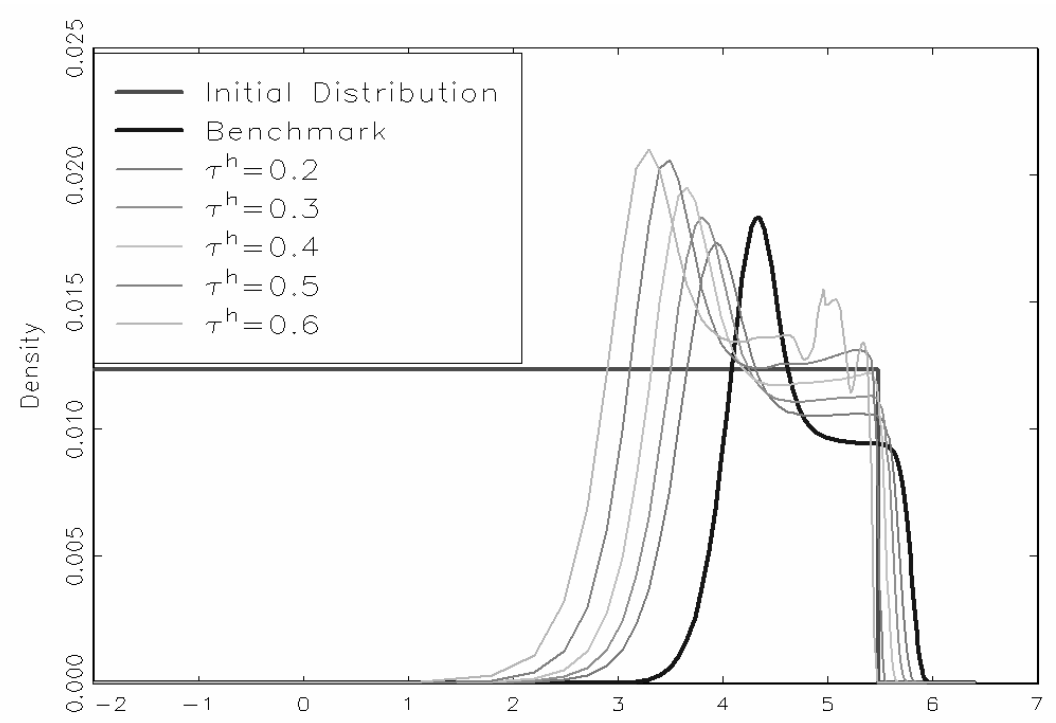

Figure 7: Logarithm Scale of Income Distribution

consequence, the wealth gap between the poor and the rich contracts and the economy is equal. On the contrary, when $\tau^{h}$ is higher, the capital accumulation is slow and the shift of poor people to the right side is slow. As a consequence, the wealth gap does not contract relatively and the economy is less equal. To present our results in an easy-to-understand format, we convert the horizontal axis in Figure 6 to logarithm form. The horizontal axis in Figure 7 shows the logarithm of asset scales. We can find that the poor move to right more than the rich do.

\subsubsection{Income Inequality and Economic Growth}

The relationship between income inequality and economic growth can be examined from the results of Figure 4 (3) and Figure 5. Figure 8 is a conceptual graph that shows both the results of the income inequality and the economic growth at the same time. We define Economy I and Economy II as the economy with high progressive tax and low progressive tax, respectively. The panel above shows the time and the economic growth rate, and the panel below shows the time and the income inequality degree. Because our model assumes no technological progress in production, the economic growth rates of the economy I and II in a steady state become 0 .

The reverse of income inequality occurs at time $t^{*} \cdot t^{\mathrm{SS}}$ shows a steady state. We define the period from initial period to time $t^{*}$ as period $\mathrm{A}$, and the period from time $t^{*}$ to a steady state as period B. In period A, the higher the economic growth rate is, the more equal the economy is. Alternatively, the more equal the economy is, the higher the economic growth rate is. On the contrary, in period B, the higher the economic growth rate is, the less equal the economy is. Alternatively, the less equal the economy is, the higher economic growth rate is. We summarize the results in Table 2 .

If we regard the countries in periods A and B as developing countries and developed countries, respectively, our results are consistent with Barro (2000)'s, which shows that the income inequality in poor countries retards economic growth, but the income inequality in rich countries encourages economic growth. Our results are also consistant with the two pair of examples - Asian and South American countries, and the United State and France. Moreover, Sukiassyan (2007) shows the negative effect of income inequality on economic growth using the data of 26 countries including 


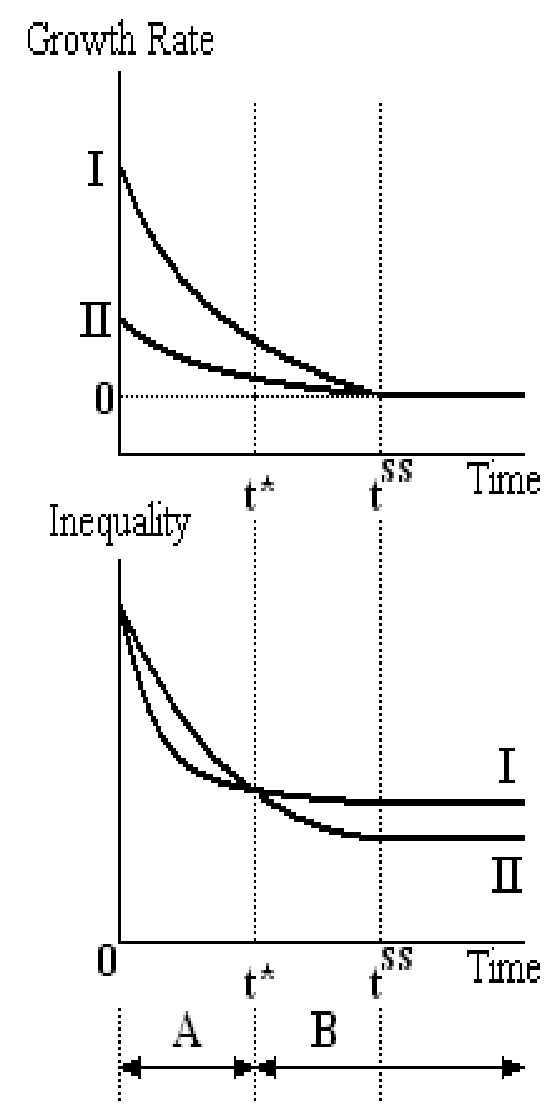

Figure 8: Conceptual Graph

Table 2: Relationship between income inequality and economic growth rate by period

\begin{tabular}{l|l|l||l|l|l}
\hline Period & Equality & Inequality & Period & $\begin{array}{l}\text { Rapid } \\
\text { Economic } \\
\text { Growth }\end{array}$ & $\begin{array}{l}\text { Low Eco- } \\
\text { nomic } \\
\text { Growth }\end{array}$ \\
\hline $\begin{array}{l}\text { Period } \\
\text { A }\end{array}$ & $\begin{array}{l}\text { Rapid } \\
\text { Economic } \\
\text { Growth }\end{array}$ & $\begin{array}{l}\text { Low Eco- } \\
\text { nomic } \\
\text { Growth }\end{array}$ & $\begin{array}{l}\text { Period } \\
\text { A }\end{array}$ & Equality & Inequality \\
\hline $\begin{array}{l}\text { Period } \\
\text { B }\end{array}$ & $\begin{array}{l}\text { Low Eco- } \\
\text { nomic } \\
\text { Growth }\end{array}$ & $\begin{array}{l}\text { Rapid } \\
\text { Economic } \\
\text { Growth }\end{array}$ & Period & Inequality & Equality \\
\hline
\end{tabular}

Eastern Europe and CIS Countries. It is thought that his result is the result of correspondence to period A.

\subsubsection{Tax System and Income Inequality}

From the panel under Figure 8, we see that it is not necessarily the case that high progressive tax rate accomplishes an equalized society. In the countries that are near a steady state (in period 
B), high progressive tax rate accomplishes an equalized society, but in the countries that are far from a steady state (in period A), low progressive tax rate accomplishes an equalized society.

We consider two effects on the narrowing income gap, by income redistribution and by economic growth. Even if the progressive tax rate $\tau^{h}$ is high in the early stage of development, the narrowing income gap by income redistribution is not so big because there are many poor people in the early stage of development. The narrowing income gap by economic growth is also not so big because the high progressive tax rate causes low economic growth. On the contrary, when the progressive tax rate $\tau^{h}$ is low in the early stage of development, the narrowing income gap by income redistribution is not so big but the narrowing income gap by economic growth is big because the high economic growth makes the poor people shift to the right side.

When the progressive tax rate $\tau^{h}$ is high near a steady state, the narrowing income gap by income redistribution is big because there are many rich people near a steady state. When the progressive tax rate $\tau^{h}$ is low near a steady state, the narrowing income gap by income redistribution is not so big. Even if the progressive tax rate $\tau^{h}$ is high or low near a steady state, the narrowing income gap by economic growth is not so big because the growth rate itself is low near a steady state. We summarize the results in Table 3.

Table 3: Income tax rate and correction of income inequlity and economic growth rate by period

\begin{tabular}{l|l||l|l|l}
\hline Period & $\begin{array}{l}\text { Maximum } \\
\text { Tax } \\
\text { Rate } \\
\left(\tau^{h}\right)\end{array}$ & $\begin{array}{l}\text { Correcting of } \\
\text { the income } \\
\text { inequality } \\
\text { by income } \\
\text { redistribution }\end{array}$ & $\begin{array}{l}\text { Correcting of } \\
\text { the income } \\
\text { inequality } \\
\text { by economic } \\
\text { growth }\end{array}$ & $\begin{array}{l}\text { Correcting of } \\
\text { the income } \\
\text { inequality by } \\
\text { both factors }\end{array}$ \\
\hline \multirow{2}{*}{ Period A } & High & Small & Small & Small \\
\cline { 2 - 5 } & Low & Small & Big & Big \\
\hline Period B & High & Big & Small & Big \\
\cline { 2 - 5 } & Low & Small & Small & Small \\
\hline
\end{tabular}

This result suggests that if we want to correct income inequality by changing the tax rate, we have to understand whether the economy is in period A or B before changing the tax rate. In case that the economy is in period $\mathrm{A}$, raising the tax rate can invite the expansion of income inequality, but not the narrowing of income inequality.

\subsubsection{Implications}

We describe a policy implication based on our results. Rapid economic growth and low income inequality are the crucial target of government policies. In the early state of development, the two government polices can be achieved simultaneously by low income tax. But near a steady state, both cannot be achieved simultaneously. If the economic growth is emphasized, the income inequality cannot be corrected, and if the income equality is emphasized, rapid economic growth cannot be achieved. There is no "killing-two-birds-with-one-stone" solution near the steady state. We should prioritize one of the two government polices. We summarize the results in Table 4. 
Table 4: Implications

\begin{tabular}{|c|c|c|c|c|c|c|}
\hline & \multicolumn{3}{|c|}{$\begin{array}{l}\text { Early stage of economic de- } \\
\text { velopment }\end{array}$} & \multicolumn{3}{|c|}{ Near a steady state } \\
\hline & Method & $\begin{array}{l}\text { Rapid } \\
\text { economic } \\
\text { growth }\end{array}$ & $\begin{array}{l}\text { Correcting } \\
\text { inequality }\end{array}$ & Method & $\begin{array}{l}\text { Rapid } \\
\text { economic } \\
\text { growth }\end{array}$ & $\begin{array}{l}\text { Correcting } \\
\text { inequality }\end{array}$ \\
\hline $\begin{array}{l}\text { Priority } \\
\text { on the } \\
\text { growth } \\
\text { rate }\end{array}$ & $\begin{array}{l}\text { Low } \\
\text { income } \\
\text { tax }\end{array}$ & $\begin{array}{l}\text { Can be } \\
\text { achieved }\end{array}$ & $\begin{array}{l}\text { Can be } \\
\text { achieved }\end{array}$ & $\begin{array}{l}\text { Low } \\
\text { income } \\
\text { tax }\end{array}$ & $\begin{array}{l}\text { Can be } \\
\text { achieved }\end{array}$ & $\begin{array}{l}\text { Cannot be } \\
\text { achieved }\end{array}$ \\
\hline $\begin{array}{l}\text { Priority } \\
\text { on cor- } \\
\text { recting } \\
\text { the in- } \\
\text { equality }\end{array}$ & $\begin{array}{l}\text { Low } \\
\text { income } \\
\text { tax }\end{array}$ & $\begin{array}{l}\text { Can be } \\
\text { achieved }\end{array}$ & $\begin{array}{l}\text { Can be } \\
\text { achieved }\end{array}$ & $\begin{array}{l}\text { High } \\
\text { income } \\
\text { tax }\end{array}$ & $\begin{array}{l}\text { Cannot } \\
\text { be } \\
\text { achieved }\end{array}$ & $\begin{array}{l}\text { Can be } \\
\text { achieved }\end{array}$ \\
\hline
\end{tabular}

\section{Conclusions}

In this paper, we examined the relationship between income inequality and economic growth. Existing literature results, both positive and negative, are reported. There remains a disagreement on the effect of the income inequality on economic growth. We attempted to make the disagreement comprehensible within a single framework. In section 2, we showed the relationship between Gini coefficient and the economic growth rate from the Kuznets curve and the convergence theory. In sections 3 and 4 , we calculated the optimal time paths of economic variables using a heterogeneous model including a progressive tax system.

The main results of this paper are the following: i) We showed that both are possible using a theoretical model that depends on the state of development. Income inequality has a negative effect on economic growth in the early stage of economic development, but income inequality has a positive effect on economic growth near a steady state as Barro (2000). We made the disagreement clear within a single model. (ii) We showed that the income redistribution by high income tax does not always reduce income inequality. Income inequality can be reduced by higher income tax near a steady state, but it cannot be reduced in an early stage of economic development. (iii) We know that two government polices can be achieved by low income tax in an early stage of economic development, but both cannot be achieved simultaneously near a steady state.

We leave the investigation of how to decide the reverse point of income inequality and the qualitative characteristics of the reverse point for a further study.

\section{Appendix}

Figure 9 and Figure 10 show the results when the initial asset distribution is a uniform distribution, which has the interval of left $15 \%$ to $25 \%$ range of $\mathcal{A}$, that is, the initial asset distribution is a uniform distribution over the interval $[90,150]$. The results are similar to what is achieved by the interval of left $40 \%$ range of $\mathcal{A}$ in Section 4.

The axes of Figure 9 and Figure 10 are drawn as the same axes in Figure 2 and Figure 3. Each vertical axis shows the density and each horizontal axis shows the asset. 
(1) Benchmark

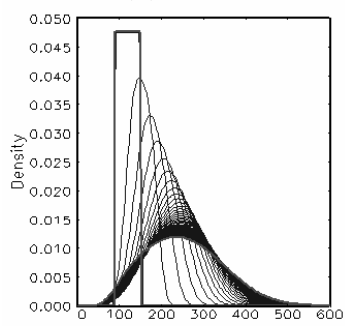

(4) $\tau^{\mathrm{h}}=0.4$

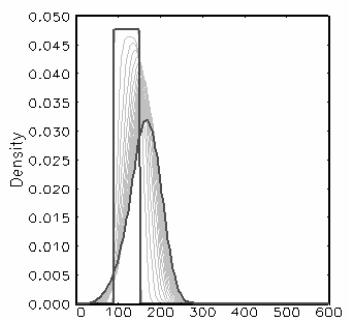

(2) $\tau^{\mathrm{h}}=0.2$

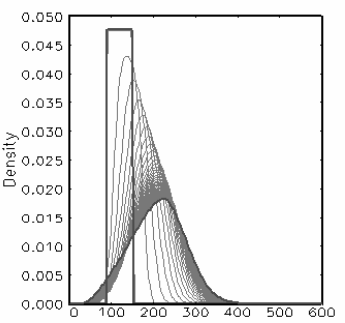

(5) $\tau^{\mathrm{h}}=0.5$

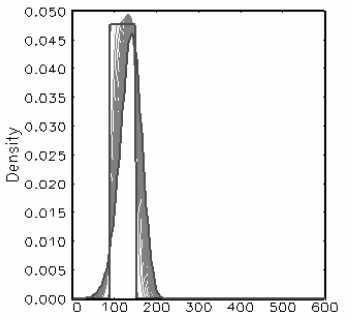

(3) $\tau^{\mathrm{h}}=0.3$

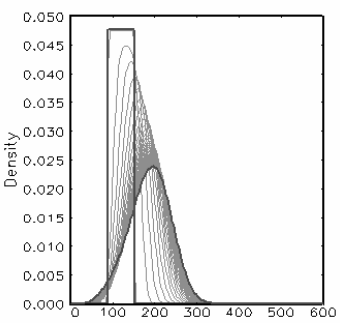

(6) $\tau^{\mathrm{h}}=0.6$

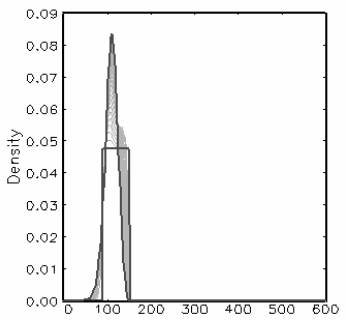

Figure 9: Dynamics of Asset Distribution

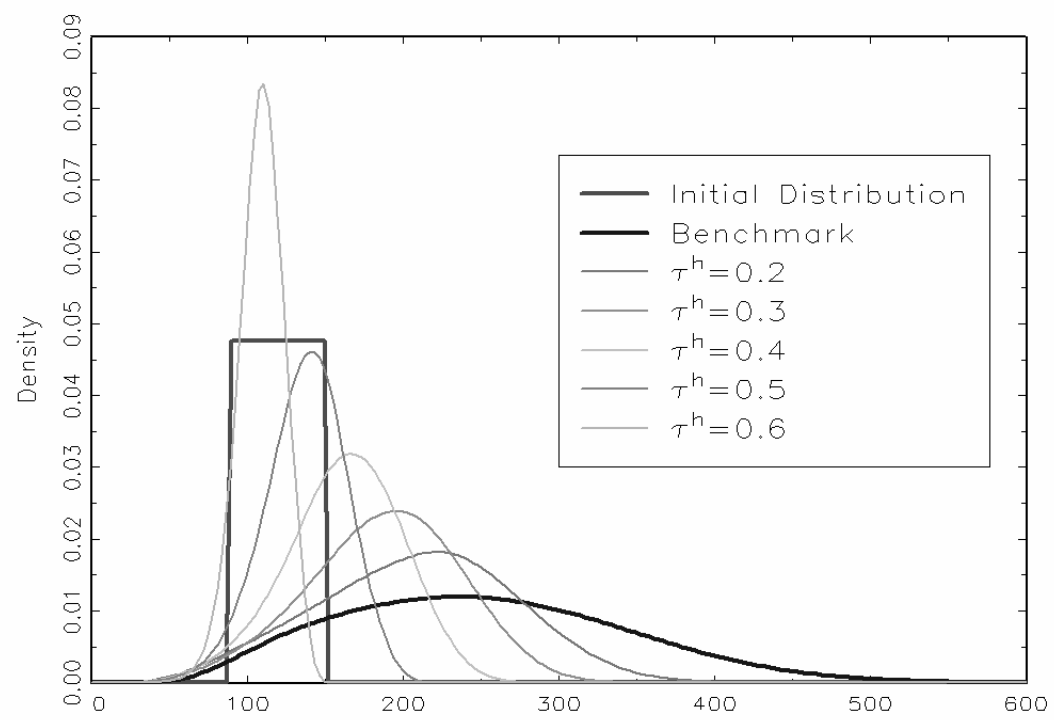

Figure 10: Comparison of Assets Distribution

\section{References}

[1] Abramovitz, M., 1986. Catching Up, Forging Ahead, and Falling Behind. Journal of Economic History 46 (2), 385-406.

[2] Acemoglu, D., 1997. Matching, Heterogeneity, and the Evolution of Income Distribution, Journal of Economic Growth 2 (1), 61-92.

[3] Aghion, P., Howitt, P., 1998. Endogenous Growth Theory, Cambridge, MIT Press. 
[4] Alesina, A., Perotti, R., 1996. Income Distribution, Political Instability, and Investment, European Economic Review 40 (6), 1203-1228.

[5] Alesina, A., Rodrik, D., 1994. Distributive Politics and Economic Growth, Quarterly Journal of Economics 109 (2), 465-490.

[6] Amos, O. M., 1988. Unbalanced regional growth and regional income inequality in the latter stages of development, Regional Science and Urban Economics 18 (4), 549-566.

[7] Banerjee, A., Duflo, E., 2003. Inequality and Growth: What can the data say? Journal of Economic Growth 8 (3), 267-299.

[8] Barro, R. J., 2000. Inequality and Growth in a Panel of Countries, Journal of Economics Growth 5 (1), 5-32.

[9] Baumol, W. J., 1986. Productivity Growth, Convergence, and Welfare: What the Long-Run Data Show, American Economic Review 76 (5), 1072-1085.

[10] Benabou, R., 1996. Inequality and Growth, in B. S. Bernanke and J. Rotemberg (Eds.), NBER Macroeconomics Annual, Cambridge, MIT Press.

[11] Bourguignon, F. J., 1990. Growth and Inequality in the Dual Model of Development: The Role of Demand Factors, Review of Economic Studies 57 (2), 215-228.

[12] Castaneda, A., Diaz-Gimenez, J., Ríos-Rull, J.-V., 1998. Exploring the Income Distribution Business Cycle Dynamics, Journal of Monetary Economics 42 (1), 93-130.

[13] Chen, B.-L., 2003. An inverted-U relationship between inequality and long-run growth, Economics Letters 78 (2), 205-212.

[14] De Long, J. B., 1988. Productivity Growth, Convergence, and Welfare: Comment, American Economic Review 78 (5), 1138-1154.

[15] Forbes, K., 2000. A reassessment of relationship between inequality and growth, American Economic Review 90 (4), 869-886.

[16] Heer, B., Maussner, A., 2005. Dynamic General Equilibrium Modelling: Computational Methods and Applications, Springer.

[17] Helpman, E., 2004. The Mystery of Economic Growth, Belknap Harvard.

[18] Judd, K. L., 1998. Numerical Methods in Economics, MIT Press.

[19] Krusell, P., Smith, A. A., 1998. Income and Wealth Heterogeneity in the Macroeconomy, Journal of Political Economy 106 (5), 867-896.

[20] Kuznets, S., 1955. Economic Growth and Income Inequality, American Economic Review 45 (1), 1-28.

[21] Li, H., Zou, H., 1998. Income Inequality Is Not Harmful for Growth: Theory and Evidence, Review of Development Economics 2 (3), 318-334.

[22] Mankiw, G. D., Romer, D., Weil, D., 1992. A Contribution to the Empirics of Economic Growth, Quarterly Journal of Economics 107 (2), 407-437.

[23] Murphy, K. M., Shleifer, A., Vishny, R. W., 1989. Income Distribution, Market Size, and Industrialization, Quarterly Journal of Economics 104 (3), 537-564. 
[24] Okun, A. M., 1975. Equality and Efficiency: The Big Trade-Off, Washington, DC. Brookings Institution.

[25] Perotti, R., 1993. Political Equilibrium, Income Distribution, and Growth, Review of Economic Studies 60 (4), 755-776.

[26] Perotti, R., 1996. Growth, Income Distribution, and Democracy: What the Data Say, Journal of Economic Growth 1 (2), 149-187.

[27] Persson, T., Tabellini, G., 1994. Is Inequality Harmful for Growth? American Economic Review 84 (3), 600-621.

[28] Ríos-Rull, J.-V., 1999. Computation of Equilibria in Heterogeneous-Agent Models. in Ramon Marimon and Andrew Scott (Eds.), Computational Methods for the Study of Dynamic Economies, Oxford, Oxford University Press.

[29] Shin, I., Kim, H., Yamamura, E., 2009. Technological Progress and the Future of Kuznets Curve's, MPRA (Munich Personal RePEc Archive) Paper No. 18866.

[30] Sukiassyan, G., 2007. Inequality and Growth: What does the transition economy data say? Journal of Comparative Economics 35 (1), 35-56.

[31] Tachibanaki, T., 2005. Confronting Income Inequality in Japan - A Comparative Analysis of Causes, Consequences, and Reform, MIT Press.

[32] Weil, D. N., 2005. Economic Growth, Addison-Wesley.

[33] Wolfson, M. C., 1994. When Inequalities Diverge, American Economic Review 84 (2), 353358.

[34] World Bank, 1993. The East Asian Miracle: Economic Growth and Public Policy, Oxford University Press. 